This is the peer reviewed version of the following article: Boyce, C. J., Wood, A. M., Delaney, L., and Ferguson, E. (2017) How do Personality and Social Structures Interact with Each Other to Predict Important Life Outcomes? The Importance of Accounting for Personality Change. Eur. J. Pers., 31: 279-290, which has been published in final form at https://doi.org/10.1002/per.2099. This article may be used for non-commercial purposes in accordance With Wiley Terms and Conditions for self-archiving. 
Running Head: PRE-EVENT PERSONALITY AS PREDICTOR

Research article: How do personality and social structures interact with each other to predict important life outcomes? The importance of accounting for personality change

Full Reference: Boyce, C. J., Wood, A. M., Delaney, L., \& Ferguson, E. (in press). How do personality and social structures interact with each other to predict important life outcomes? The importance of accounting for personality change. European Journal of Personality.

Final pre-publication copy as sent to the publisher with whom the copy of record and copywrite resides.

Corresponding author details

Name: Christopher Boyce

Email: christopher.boyce@stir.ac.uk

Telephone: +44 (0) 1786467379

Address: Behavioural Science Centre, Stirling Management School, University of Stirling, Stirling, FK9 4LA.

Competing Interest Statement

The authors have no competing interests to report. The Economic and Social Research Council provided research support (ES/K00588X/1). The data were made available by the German Institute for Economic Research (DIW Berlin). Neither the original collectors of the data nor the Archive bears any responsibility for the analyses or interpretations presented here. 
Running Head: PRE-EVENT PERSONALITY AS PREDICTOR

How do personality and social structures interact with each other to predict important life outcomes? The importance of accounting for personality change

\author{
Christopher J. Boyce
}

Behavioural Science Centre, Stirling Management School, University of Stirling, Scotland,

\author{
Alex M. Wood
}

Behavioural Science Centre, Stirling Management School, University of Stirling, Scotland, and School of Psychological Sciences, University of Manchester, England

$$
\text { Liam Delaney }
$$

Behavioural Science Centre, Stirling Management School, University of Stirling, Scotland

$$
\text { Eamonn Ferguson }
$$

School of Psychology, University of Nottingham, England 
Running Head: PRE-EVENT PERSONALITY AS PREDICTOR

\begin{abstract}
Personality is important for a range of life outcomes. However, despite evidence that personality changes across time, there is a concerning tendency for researchers outside of personality psychology to treat measures of personality as if they are non-changing when establishing whether personality predicts important life outcomes. This is problematic when personality changes in response to outcomes of interest and creates a methodological issue that may result in misleading conclusions. We illustrate this methodological issue and suggest using measures before the outcome takes place to mitigate concerns. We then demonstrate, using data from Germany that using post-event personality measures, as opposed to preoutcome measures, to predict both occurrence of, and reactions to, socio-economic events results in inconsistent conclusions in the directions hypothesized and therefore increases the likelihood of Type 1 and Type 2 errors. This has implications for research investigating the importance of personality for psychological, behavioral, and socio-economic outcomes.
\end{abstract}


Running Head: PRE-EVENT PERSONALITY AS PREDICTOR

\section{How do personality and social structures interact with each other to predict important life outcomes? The importance of accounting for personality change}

The availability of personality scales in large nationally representative longitudinal datasets has created many new research possibilities for understanding how personality relates to important life outcomes. Researchers are now able to better understand, for example, how early life personality characteristics relate to later life events (Daly, Delaney, Egan, \& Baumeister, 2015; Egan, Daly, Delaney, Boyce, \& Wood, in press), how personality develops in response to social conditions (Boyce, Wood, Daly, \& Sedikides, 2015; Specht, Egloff, \& Schmukle, 2011), the extent to which effects found in small studies generalize at the population level (Donnellan \& Lucas, 2008), how personality develops over the life course (Lucas \& Donnellan, 2011), and how personality predicts well-being response following important life events (Boyce \& Wood, 2011b; Boyce, Wood, \& Brown, 2010; Pai \& Carr, 2010). Further, the appearance of personality scales in large longitudinal datasets, which are more commonly used outside of psychology, has helped introduce personality research to disciplines that have traditionally focused more on social determinants of life outcomes. Economists, for example, now recognise that there is a strong theoretical case for including personality in their modelling (Borghans, Duckworth, Heckman, \& Weel, 2008; Rustichini, DeYoung, Anderson, \& Burks, 2012) and in turn economists have introduced important methodological advances to personality psychology (Heckman, Malofeeva, Pinto, \& Savelyev, 2007; Heckman, Pinto, \& Savelyev, 2013).

However, with the likely increase in use of personality measures in large datasets to understand social phenomena there is a need to ensure that the knowledge base within personality psychology is fully extended to other areas of psychology and other disciplines to avoid conceptual and methodological mistakes. One such common mistake outside of personality psychology is conceptualizing personality as being fixed (see Ferguson, 2013; Ferguson \& Lievens, in press). There is a concerning tendency for researchers to not fully consider that an important life outcome or social situation under consideration may have not only been influenced by personality but critically may have itself influenced personality. This becomes problematic when personality is measured after the outcome under investigation has taken place, as the personality measure may potentially be contaminated by the outcome itself having occurred. A preferable analysis to understand how personality contributes to the occurrence of various life outcomes would therefore be to ensure personality was measured prior to the outcome occurring. Here we demonstrate that analyses using measures of 
personality taken after the occurrence of an outcome are likely to contain both Type 1 and Type 2 errors leading to incorrect and potentially misleading conclusions. This has important implications for the use of personality to understand the role of an individual's personal and social conditions.

The notion of a fixed personality stems from early conceptualizations of personality as representing primarily biological and genetic differences between individuals (McCrae, Costa, Ostendorf, Angleitner, \& Avia, 2000). Thus there was initially a general belief that personality changed early in life through a natural maturation process but became "set like plaster" at approximately the age of 30 (Costa \& McCrae, 1994; Srivastava, John, Gosling, \& Potter, 2003). The view that personality is "set like plaster" permeated the field for some time but with mounting evidence showing that personality evolves throughout all stages of the life-cycle (Lucas \& Donnellan, 2011; Roberts, Walton, \& Viechtbauer, 2006a) this view has largely been overturned (see Costa \& McCrae, 2006; Roberts, Walton, \& Viechtbauer, 2006b). Personality also changes with respect to more proximal events like work (Roberts, Caspi, \& Moffitt, 2003), going to university (Lüdtke, Roberts, Trautwein, \& Nagy, 2011), health difficulties (Jokela, Hakulinen, Singh-Manoux, \& Kivimäki, 2014), and training (Jackson, Thoemmes, Jonkmann, Lüdtke, \& Trautwein, 2012). Within personality psychology the important role of time in the personality change process is well-documented (Luhmann, Orth, Specht, Kandler, \& Lucas, 2014). However, outside of the immediate field there is still some notion that personality is more or less fixed (Ferguson \& Lievens, in press). In part this has arisen due to non-shared definitional differences as to what personality is. For example, if one understands personality to represent the non-changing aspects of a person then personality change would not be possible owing simply to terminological barriers (see Boyce et al., 2015, who make a similar argument within the applied psychology literature). Thus any appearance of change suggests that whatever has changed can no longer be referred to as personality.

Personality psychologists tend to define personality broadly as encompassing "the psychological component of a person that remains from one situation to another" (A. M. Wood \& Boyce, 2014). This definition implies a degree of both temporal and crosssituational stability suggesting that whilst personality may be largely stable the possibility of change is not precluded. Personality includes specific characteristic beliefs individuals hold 
about themselves and the world ("schemas"), their preferences, and their resultant behavior 1 patterns (Caspi \& Shiner, 2007). Such resultant behavior patterns arise from the complex interaction between all of these elements of an individual's personality, as well as the environment and culture in which the person lives (Rentfrow, Gosling, \& Potter, 2008; Roberts, Wood, \& Caspi, 2008). Although resultant behavior patterns can vary from moment to moment depending on the social situation individuals can be reliably distinguished from one another by the mean point of their personality expression distribution (Fleeson, 2001, 2004), which is to what people refer when asked about their personality "in general". Thus, whilst there is a stable component to an individual's personality, were an individual to find themselves chronically in a different social situation, for example, through becoming unemployed or widowed when they were respectively previously employed or in a stable marriage, then personality could reasonably be expected to change.

Under this perspective of personality change taking place due to shifting social situations, then it matters when personality is measured for predicting the future occurrence of that event. If personality were measured after the occurrence of any major life event, which then completely changed an individual's circumstances, then the post-event measure of personality will likely be different to personality before the occurrence of that life event. It is also the case that not everyone will experience equal amounts of personality change following the occurrence of the life event, and indeed individual difference in the degree of personality change have themselves been noted (Lüdtke et al., 2011). Any post-event measure of personality will therefore be contaminated by the occurrence of the new circumstance and will result in misleading and biased conclusions as to whether or not personality precipitated the new life situation in the first place. For example, there is evidence to suggest that unemployment is associated with reductions in agreeableness, conscientiousness, and openness (Boyce et al., 2015). Thus whilst those with low agreeableness, conscientious and openness may have been more likely to have experienced unemployment previously this does not necessarily mean that employed individuals who are low in agreeableness, conscientiousness and openness are at the most risk of unemployment. Nevertheless, despite the expectation that personality could change there are already a number of published papers outside the immediate sub-field of personality psychology in which researchers have investigated the extent to which personality predicts important life

\footnotetext{
${ }^{1}$ We use "behavior" here to refer to both "external" behaviors such as following through on goal directed activity, and "internal" such as specific occasions of emotions; in both cases the externally visible characteristic that is being referred to.
} 
outcomes such as unemployment duration (Uysal \& Pohlmeier, 2011), wages (Heineck, 2011; Heineck \& Anger, 2010), as well as well-being reactions to socio-economic events (Proto \& Rustichini, 2015; Soto \& Luhmann, 2013; Yap, Anusic, \& Lucas, 2012) with little or no consideration for the possibility that the outcomes which are being investigated may have themselves resulted in changes to personality. This tendency can be attributed in part to data limitations. Personality measures are a relatively novel component of large nationally representative datasets that have spanned many other topics across many years. Personality questionnaires have typically been included in a one-off fashion, under the assumption that a personality measure taken at one time point is a suitable proxy for personality measured across the entire study period. Many researchers have uncritically adopted this assumption and given the rise in use of such datasets in psychology there is a risk that the fixed personality assumption could become normative within this research stream.

However, there are other studies that use large nationally representative longitudinal datasets to ask similar questions that have been explicit about their assumptions regarding personality change (e.g., Boyce \& Wood, 2011a, 2011b; Boyce et al., 2010; Boyce, Wood, \& Ferguson, 2016b, 2016a; Daly et al., 2015; Egan et al., in press; Kesavayuth, Rosenman, \& Zikos, 2015; Pai \& Carr, 2010). Such studies have ensured that personality is at least measured prior to the outcome in which they are interested. Although a personality measure before the occurrence of an outcome is dependent on social circumstances at the time, as well as previous experiences of the outcome, the use of a pre-outcome measures of personality are more informative for understanding the role of personality in predicting the outcomes future likelihood. In this paper we demonstrate the methodological issue that arises from not accounting for potential development in personality that may have taken place as a result of occurrence of a specific outcome when exploring the role of personality in predicting that outcome. We show that this may result in both Type 1 and Type 2 errors and we surmise when this will be most problematic. We then explore the problem empirically with a dataset which contains both pre- and post-event measures of personality to examine the extent to which pre- or post-event personality measures predict not only the occurrence of a socioeconomic event but also the well-being reactions to these same socio-economic events. In understanding which individuals might be the most susceptible to a socio-economic circumstance we conclude that pre-outcome measures of personality are essential.

\section{Method}


We are interested in some outcome, $y$, for example becoming unemployed or wellbeing, which is determined as follows:

(1) $\mathrm{y}_{\mathrm{it}}=\beta_{0}+\sum_{k=1}^{k} \beta_{k} x_{k i t}+P_{i t}+P_{i t} * \sum_{k=1}^{k} \beta_{k} x_{k i t}+\sum_{k=1}^{k} \beta_{j} z_{j i t}+\mu_{\mathrm{i}}+\delta_{\mathrm{t}}+\varepsilon_{\mathrm{it}}$

where outcome y for individual, $i$, at time, $t$, depends on $k$ socio-economic conditions, $x$, and $j$ correlated factors, $z$, individual heterogeneity (i.e. factors that vary between individuals but do not vary across time), $\mu$, specific time period effects, $\delta$, and an error component, $\varepsilon$. Measureable individuals differences, such as personality, $P^{2}$, are also believed to be an important predictor of the outcome. Under the assumption that personality is fixed $\left(P_{i t}=P_{i}\right)$ the individual heterogeneity, $\mu_{i}$, subsumes these individual differences and may get referred to as unobservable or unknown individual heterogeneity (see Boyce, 2010 where this issue is explored in depth). If the only concern were with eliminating individual heterogeneity as a source of estimation bias then unbiased estimates for equation 1 can be easily obtained by a model that focuses on explaining the within-person variation (Angrist \& Pischke, 2008). However, if it were believed that there is also individual heterogeneity in the outcome which can be explained by a measureable constructs, such as personality, then we can obtain appropriate measures and interact these with the main effect. Under the assumption that personality is fixed $\left(P_{i t}=P_{i}\right)$ we would need measures at only one time point to carry out such an analysis.

An analytical concern arises, however, when the assumption that personality is fixed is violated. As already outlined empirical evidence suggests that this assumption is indeed violated (Lucas \& Donnellan, 2011; Roberts, Walton, \& Viechtbauer, 2006a). In fact personality has been shown to change at least as much as socio-economic circumstances (Boyce, Wood, \& Powdthavee, 2013; Hounkpatin, Wood, Boyce, \& Dunn, 2014) and even more importantly that this change takes place in response to changes to socio-economic circumstances (Boyce et al., 2015; Heckman, Malofeeva, Pinto, \& Savelyev, 2007; Heckman, Pinto, \& Savelyev, 2013; Specht et al., 2011; Specht, Egloff, \& Schmukle, 2013). Thus personality may be dependent upon the same factors that determine the outcome of interest:

\footnotetext{
${ }^{2} \mathrm{P}$ might be a number of aspects of personality, such as the Five Factor Model of personality whereby $\mathrm{P}$ will represent a vector of the five personality dimensions
} 


$$
\text { (2) } P_{i t}=\beta_{0}+P_{i 0}+\sum_{k=1}^{k} \beta_{k} x_{k i t}+\sum_{k=1}^{k} \beta_{j} z_{j i t}+\delta_{\mathrm{t}}+\varepsilon_{i t}
$$

Whilst there is no doubt a fixed component to an individual's personality, $P_{i 0}$, (Bouchard \& McGue, 2003) personality is also determined, much like the outcome of interest in equation 1 , by other factors such as $k$ socio-economic conditions, $x$, and $j$ correlated factors, $z$, time period effects, $\delta$, and an error component, $\varepsilon$. Therefore to be correctly specified equation 1 has to take account of changes to an individual's personality. Personality change, $P_{i t}$, may enter into equation 1 both directly and via the interaction term and, if the change is correlated with the outcome variable and this change is not correctly accounted for an endogeneity issue arises. Ideally we would need measures at multiple time-points to fully deal with this problem but, owing to the assumption that personality does not develop in later life, appropriate measurement typically takes place at only relatively few time-points in large representative datasets. However, the problem we have outlined here is substantially mitigated by ensuring any measures of personality are taken at some point before any change to an individual's circumstances, preferably immediately before, rather than at any point after.

First, if we wish to predict the occurrence of a socio-economic outcome it is clear that if a certain measure changes as a result of the socio-economic outcome then it is likely to also post-hoc predict the occurrence of the socio-economic outcome in some way. For example, if the experience of unemployment reduces an individual's conscientiousness then low conscientiousness measured following the unemployment experience is more likely to predict unemployment than if conscientiousness were measured before the event. The extent of this problem is dependent only upon the degree to which the socio-economic situation changes personality but will result in misleading conclusions as to whom the change in socioeconomic circumstances is likely to happen to.

Second, with respect to predicting an individual's reaction to a change in socioeconomic circumstances, a problem occurs with post-event measures if both the change in the outcome, $\mathrm{y}$, and the change in any personality measures are dependent upon the change of socio-economic circumstance. In this situation the extent of the problem is dependent upon not only the extent to which the socio-economic change leads to personality change, as with predicting the occurrence of the socio-economic circumstance changes, but also the degree to which the socio-economic event changes the outcome, and the correlation between the 
changes that occur in both the personality and the outcome. Again measures used before the occurrence of the socio-economic event would help to avoid this concern.

We proceed to illustrate this problem empirically using data from Germany. We examine the extent to which personality, as measured via the FFM, predicts the occurrence of various socio-economic circumstances, as well as an individual's well-being reaction to these changes in circumstances, and whether it matters if personality is measured before or after the occurrence of the socio-economic change.

All our analyses are carried out using Ordinary Least Squares (OLS). An alternative would be to carry out Structural Equation Modelling (SEM), which allows researchers to account for measurement error by building any scale unreliability directly into the model. However, for our research question an OLS approach is preferable to SEM since (a) there is high degree of model complexity (multilevel and a large number of parameters, including interaction terms) that may make it difficult to find stable models that include both a measurement component and a structural one, (b) there are only two time-points of personality data our model, which would limit assessment using an SEM to a latent change model, (c) there is a likelihood of a poor fitting measurement model as the measurement model does not account for cross-loadings (Zhao, Ferguson, \& Smillie, in press), and (d) our sample is relatively large and there is therefore likely to be asymptotic equivalence across models.

Data

We use the German Socio-Economic Panel Study (SOEP), an ongoing longitudinal study of German households. The SOEP began in 1984 with a sample of adult members from randomly selected households in West Germany. Since 1984, the SOEP has expanded to include East Germany and also added various sub-samples to maintain a representative sample of the entire German population (see Wagner, Frick, \& Schupp, 2007). We focused on a sub-sample of SOEP participants who answered questions on their personality in both 2005 and 2013. We therefore construct a 9 wave panel where FFM measures of personality, are measured at the first time-point and again at the final time-point. We use each of the measures to explore the extent to which we can predict both the occurrence of socioeconomic circumstances and reactions to them. Our overall sample includes 85,280 observations from 9,574 participants across the time-period (53\% female, age 16 to $103, M=$ $51.55)$. 
Personality was measured using a shortened version of the Big Five Personality Inventory (Benet-Martínez \& John, 1998) which was administered in both 2005 and 2013. This version, shown in the Appendix, was developed specifically for use in the SOEP, where space for survey questions is severely limited (Gerlitz \& Schupp, 2005). Participants responded to 15 items $(1=$ does not apply to me at all, $7=$ applies to me perfectly scale $)$, with three items assessing each of the five domains of agreeableness (e.g., "has a forgiving nature"), conscientiousness (e.g., "does a thorough job"), extraversion (e.g., "is communicative, talkative"), neuroticism (e.g., "worries a lot"), and openness (e.g., "is original, comes up with new ideas"). The SOEP scale has comparable psychometric properties to similar but longer personality scales. For example, using different assessment methods, Lang, John, Lüdtke, Schupp, and Wagner (2011) showed that the short-item scale produces a robust five factor structure across all age groups. Donnellan and Lucas (2008) demonstrated that each of the scales contained in the SOEP correlates highly (at least $r=.88$ ) with the corresponding sub-scale of the full Big Five Inventory. Also, Lang (2005) illustrated that the retest reliability of the scale across 6 weeks is acceptable (at least $r=0.75$ ). Aggregate scores of each personality dimension were calculated and standardized $(M=0, S D$ $=1)$.

Socio-economic circumstances. In each year of the SOEP participant's current marital status and occupational status are recorded. We specifically analyze unemployment, retirement, marriage, separation, divorce, and widowhood

Subjective well-being was captured across all years using a one-item life satisfaction scale: "how satisfied are you with your life, all things considered?" from 0 (completely dissatisfied) to 10 (completely satisfied). Participants responses $(M=7.02, S D=1.71)$ were standardized $(M=0, S D=1)$.

Covariates. Since personality, well-being, and socio-economic circumstances are likely correlated with a number of other observable characteristics we include additional socio-demographic variables in our analyses. These include year and regional dummy variables, sex, age, age $^{2}$, age $^{3}$, years of education, log of household income, log of household size, and disability status, which we included as control variables. 
Running Head: PRE-EVENT PERSONALITY AS PREDICTOR

Missing data

Of those individuals that answered questions about their personality at both timepoints there was some missing data in marital status (0.6\%), occupational status $(0.9 \%)$, life satisfaction $(0.2 \%)$, education $(3.1 \%), \log$ of household income $(3.8 \%)$, and disability status $(0.2 \%)$. Unless these items are missing completely at random, listwise deletion, or imputing sample wide or item averages have been shown to lead to biased estimates (Schafer \& Graham, 2002). For those that did not report their occupational or marital status we included additional dummies to indicate whether each variable was missing. We dealt with the remaining missing data using multiple imputation (Rubin, 2004). Specifically, we used multiple imputation chained equations (MICE; White, Royston, \& Wood, 2011), which is a technique whereby for each of the multiple imputations a series of sequential regressions are carried out in an iterative fashion. To limit the imputed values to within their possible score ranges for life satisfaction, education, and log of household income we used a predictive mean matching approach. We obtained 5 imputations (based on five sequential iterations using MICE) and we pooled each of our imputations to produce our final estimates.

\section{Results}

First, given the correlations in the dataset, we begin by making some predictions as to how we expect post-event personality will lead to biased conclusions. We then proceed to examine whether these predictions are realized by examining both the occurrence of and the well-being reaction to socio-economic circumstances.

\section{Empirical predictions based on the data}

As outlined above the extent of the methodological concern for both the occurrence of and reaction to will be dependent upon whether the socio-economic circumstance is likely to produce an increase or decrease on the personality score. We therefore begin by observing the extent to which the occurrence of any socio-economic change predicts changes in our measures of personality. In Table 1 we assess whether the occurrence of a socio-economic event at any time-point in our dataset predicts change in our measures of personality. Here we see that some change does arise as a result of socio-economic events and this is particularly relevant for changes in conscientiousness, agreeableness, and neuroticism. As such we may expect to see the biggest differences using pre- and post-event personality to arise in conscientiousness, agreeableness, and neuroticism. 
We further predicted in the case of a reaction to the change in socio-economic circumstance that the problem would further depend upon the correlation between the changes in personality and outcome that arise from the socio-economic event. We thus observe in Table 2 the bivariate correlation between the change in both our measures of personality and life satisfaction after nine years. Changes in neuroticism have the strongest relationship with changes in life satisfaction and this suggests that the largest differences will occur from using pre- and post-event neuroticism. More precisely, and to explain the mechanism by which we may expect to see a misleading result, a negative (positive) change in socio-economic conditions may lead to both an increase (decrease) in neuroticism and a decrease (increase) in well-being. Thus the individuals that experienced the largest decreases (increases) in well-being are also likely to exhibit the largest increases (decreases) in neuroticism. The use of a post-event measure of neuroticism, as opposed to pre-event, is therefore more likely to predict larger falls (smaller increases) in well-being (i.e., increase the likelihood of a negative interaction effect). Such a conclusion would reveal nothing about who may be the most influenced by some intervention, rather merely illustrate that those that suffered the most suffered the most.

We may also see some well-being differences in the reaction to the socio-economic circumstance in the remaining FFM traits since all are positively related to life satisfaction. This is particularly so for agreeableness and conscientiousness which were additionally shown to change in response to socio-economic events. Therefore, by similar reasoning if the occurrence of a socio-economic event results in changes to these traits, which are positively correlated with changes in well-being, we would expect to see post-event measures of these traits following a positive (negative) socio-economic event to predict larger increases (smaller decreases) in well-being (i.e., increase the likelihood of a positive interaction effect). Again a significant interaction using a post-event measure may not be meaningful.

\section{Predicting the occurrence of socio-economic events}

We begin by first exploring whether personality predicts the occurrence of unemployment, retirement, marriage, separation, divorce, or widowhood between 2005 and 2013 in Table 3. For each socio-economic event we first examine whether personality measured in 2005 predicts the socio-economic events later occurrence (columns 1, 3, 5, 7, 9, 11). We then examine whether the prediction changes using personality measured in 2013 (columns 2, 4, 6, 8, 10,12). Overall we observe that there are seven significant $(p<0.05)$ predictors using pre-event measures compared with only four using post-event. We further 
observe that there are seven coefficients using post-event measures, although not necessarily individually significant, that are significantly different from the coefficient in the pre-event model (via $\chi^{2}$ test across coefficients, where those at $p<0.05$ are emboldened). More specifically we observe that pre-event openness $(p<0.10)$, conscientiousness $(p<0.10)$, agreeableness, extraversion, and neuroticism predict the occurrence of unemployment whereas using post-event measures it is only neuroticism that remains statistically linked to unemployment's occurrence. Further, the coefficient on conscientiousness is significantly different across the models. The remaining socio-economic events follow a similar pattern, with many of the pre-event personality traits no longer important if post-event measures are used. Some traits become important where they previously were not and there is evidence that coefficients differ across the models. Since neuroticism was shown to be the trait most likely to change in this dataset (Table 3) we predicted that neuroticism would be the trait to exhibit the largest differences depending on when personality was measured. Indeed neuroticism was the trait most likely to predict the occurrence of the event and this differed somewhat depending on when personality was measured. Unemployment, separation, widowhood, and retirement $(p<.10)$ all changed neuroticism and we see in Table 4 that there are differences in the ability of neuroticism to predict these socio-economic events when neuroticism is measured before versus after the event. Overall, under the assumption that preevent measures represent the true personality picture, this suggests there are eight Type 2 errors and four Type 1 errors when using post-event measures of personality.

\section{Predicting the well-being reaction to socio-economic events}

In Table 4 we explore in a 9 wave panel how the occurrences of socio-economic circumstances influence life satisfaction. We interact our standardized personality measures with our socio-economic events such that significance on any of the interaction terms indicates that there is a prediction of individual reactions to that specific socio-economic event. We carry out two estimations. The first uses personality at the start of the 9 wave panel (regression 1); whilst the second uses measures at the end of the 9 wave panel (regression 2). In every other respect the data used in the regressions is identical; thus any interaction differences can be attributed to the time-point in which our indicator of personality was measured. The excluded dummies respectively are those that are single and never married and those that are employed. We analyze the within person variation in the data and account for clustering at the individual level (Cameron \& Miller, 2015). 
In regression 1, which uses pre-event measures, there are 4 significant interaction effects $(p<.05)$. In regression 2 there are 6 significant interaction effects $(p<.05)$. However, only 2 interactions are the same across both regressions suggesting the time-period in which our personality indicators were measured does matter. This suggests, under the assumption that pre-event measures represent the true personality picture, that the reliance on only postevent measures would have generated two Type 1 errors and four Type 2 errors. Further, using Stata's (StataCorp, 2011) "suest" command on time-demeaned data to carry out a $\chi^{2}$ test on differences in the coefficients, we observe that three of the interaction coefficients are significantly different across the models at $p<.05$ and another three at $p<.10$. Since neuroticism is the trait most strongly related to life satisfaction and also more likely to change following a socio-economic event we predicted that we would observe a negative interaction effect when we use post- rather than pre-event measure for neuroticism. We observe in regression 1, using pre-event measures, that being neurotic predicts the life satisfaction response (a positive interaction effect) of only separation. Neuroticism does not appear to be important for any other socio-economic event. However, when we look at the interactions using post-event neuroticism there is evidence of a negative interaction for both retirement and divorce, where previously there was not. In addition the previously positive coefficient on the neuroticism-separation interaction is now negative (although insignificant). Further, although only indicative, as the effect is not individually significant, the coefficient on widowhood reverts from being positive with pre-event neuroticism to being negative using post-event neuroticism.

We generally expected there to be more tendencies toward positive interactions using post-event measures for the traits agreeableness, conscientiousness, extraversion, and openness. Although misleading effects are perhaps less likely with these traits since their correlation with changes in life satisfaction is weaker (see Table 3) we do observe across all events, although not always significant, the tendencies predicted. For conscientiousness all the interactions become more positive. For extraversion this is apparent across all events except unemployment. There are some clear tendencies toward positive interaction effects for agreeableness. For example, there are negative significant effects on the agreeablenessmarriage and agreeableness-divorce interactions that are no longer present due to becoming less negative using post-event agreeableness. Widowhood reverts from being negative with pre-event agreeableness to being positive using post-event agreeableness. Although there is no evidence that agreeableness is an important moderating variables using pre- or post-event measures of personality there is borderline evidence that there is a difference $(p<.10)$ across 
measures. Openness, however, did not conform to our predictions displaying the opposite effect with a consistent tendency toward negative interaction effects. Changes in openness, however, correlate the least with life satisfaction. It is perhaps likely that individuals who experienced the greatest difficulty and reacted the most strongly with respect to life satisfaction may have also developed their levels of openness due to new situations that they now faced.

\section{Conclusion}

Personality is an important predictor of socio-economic circumstances and much recent research has utilized large representative datasets to illustrate his. Here, we illustrate the need for this literature to consider that personality may also change in response to those same circumstances and may result in misleading predictions as to how individuals might be expected to respond. First, we highlighted the endogeneity problem associated with not considering change and suggested, particularly in the presence of limited longitudinal measures in representative datasets, the use of pre-event measures to mitigate this problem. We then illustrate the problem empirically in a dataset from Germany after making several predictions as to how personality will differ from the results using post-event measures resulting in both Type 1 and Type 2 errors.

Our predictions were largely borne out when predicting both the occurrence of a socio-economic event as well as the well-being reaction to that event. For the occurrence of a socio-economic event our data illustrated that many events were predictable from pre-event measures of personality but not post-event measures. This suggests that under certain circumstances researchers may undervalue the importance of personality in explaining differences in outcomes. This may explain why some researchers have found that personality effects are small or non-existent (Becker, Deckers, Dohmen, Falk, \& Kosse, 2012; Caliendo, Mahlstedt, \& Mitnik, 2014). For the well-being reactions to the socio-economic events we generally found large inconsistencies using pre- and post-event measures and these differences were in the directions predicted. Neuroticism was particularly problematic due to the likelihood that it will change following many socio-economic events. Openness-toexperiences on the other hand directly contradicted our predictions possibly because greater adversity following a difficult experience is likely to lead to increased openness-toexperience in the individual. Overall our research suggests that by not considering the possibility of personality change for any moderation analysis will result in misleading and predictably biased conclusions. 
Our primary concern in this paper is to highlight an issue that should concern those working in the field. Already a number of researchers have published work that has not appropriately considered the possibility of changes in personality and relied on post-event measures leading to potentially unreliable conclusions (e.g., Heineck, 2011; Heineck \& Anger, 2010; Proto \& Rustichini, 2015; Soto \& Luhmann, 2013; Uysal \& Pohlmeier, 2011; Yap et al., 2012). Our findings, for example, may explain why this previous research has found either mixed patterns of results (Yap et al., 2012) or an important role for the trait neuroticism (Proto \& Rustichini, 2015; Soto \& Luhmann, 2013). Our research suggests these findings are likely to be the product of Type 1 and Type 2 errors. It is important to avoid such problems in the future and give the potential of personality change across the life course more careful consideration. It is particularly important to highlight the issue of not fully accounting for personality change to those utilizing large longitudinal datasets. In recent years there has been a rapid rise in the use of such datasets in psychology and such datasets are becoming a valuable tool in helping to understand important links between personality and social structures.

There are a number of limitations with the empirical component of our research. For example, owing to the thus far limited inclusion of personality measures in large datasets, we were restricted by the time horizon in which to assess the relationship between our measures and the occurrence of the socio-economic change. This reduced our ability to detect the changes arising specifically from each of the events. Although measures of personality directly before and after the occurrence of an event might have been preferable it remains difficult to fully account for the influence of an event on personality owing to the likelihood of non-linear and discontinuous change, potential effect reversibility, and anticipatory change (Luhmann et al., 2014). Since we were unable to account for this important role of time in our study we may have underestimated the extent to which personality changes and therefore the true extent of this problem.

A related concern is that a pre-event personality measure may be potentially confounded by previous experiences of the event. For example, an individual, although employed at the time of the personality measurement, may have experienced unemployment previously and thus this raises some concerns as to whether there is a true personality measure that is not confounded. Whilst some researchers have used childhood or adolescent personality to predict future life outcomes (e.g., Daly et al., 2015; Egan et al., in press) we were only able to define pre-event personality via the earliest measure in our dataset. Thus 


\section{Running Head: PRE-EVENT PERSONALITY AS PREDICTOR}

the empirical analysis is hampered by whether our pre-event measures can truly be considered pre-event (see Luhmann et al., 2014, for a related discussion). Whilst a conceptual difficulty this is also in part a data limitation and due to the nature of personality development across the life-cycle in response to social situations, personality measures need to be routinely included in large nationally representative datasets at regular and more frequent time intervals.

Nevertheless these concerns do not invalidate pre-event personality measures (preferably immediately before the occurrence of life event) being preferable to post-event measures when predicting important future life outcomes. The purpose of the empirical component of our research is for illustrative purposes with the main contribution of this paper to highlight to researchers outside of the immediate sub-discipline of personality psychology the methodological concern that needs to be appropriately considered and accounted for when carrying out this type of research. Our research suggests not only that personality can help understand for whom a specific event may be more likely to occur or invoke a more severe reaction to but that it is important to use pre-event measures when investigating this. A prediction of how individuals react to socio-economic events may have important implications for policy design and help highlight ways in which individuals might develop resilience. 
Running Head: PRE-EVENT PERSONALITY AS PREDICTOR

\section{References}

Angrist, J. D., \& Pischke, J.-S. (2008). Mostly Harmless Econometrics: An Empiricist's Companion. Princeton University Press.

Becker, A., Deckers, T., Dohmen, T., Falk, A., \& Kosse, F. (2012). The relationship between economic preferences and psychological personality measures. Annual Review of Economics, 4, 453-478. https://doi.org/10.1146/annurev-economics-080511-110922

Benet-Martínez, V., \& John, O. P. (1998). Los Cinco Grandes across cultures and ethnic groups: Multitrait-multimethod analyses of the Big Five in Spanish and English. Journal of Personality and Social Psychology, 75, 729-750. https://doi.org/10.1037/0022-3514.75.3.729

Borghans, L., Duckworth, A. L., Heckman, J. J., \& Weel, B. ter. (2008). The economics and psychology of personality traits. Journal of Human Resources, 43, 972-1059. https://doi.org/10.3368/jhr.43.4.972

Bouchard, T. J., \& McGue, M. (2003). Genetic and environmental influences on human psychological differences. Journal of Neurobiology, 54, 4-45. https://doi.org/10.1002/neu.10160

Boyce, C. J. (2010). Understanding fixed effects in human well-being. Journal of Economic Psychology, 31, 1-16. https://doi.org/10.1016/j.joep.2009.08.009

Boyce, C. J., \& Wood, A. M. (2011a). Personality and the marginal utility of income: Personality interacts with increases in household income to determine life satisfaction. Journal of Economic Behavior \& Organization, 78, 183-191. https://doi.org/10.1016/j.jebo.2011.01.004

Boyce, C. J., \& Wood, A. M. (2011b). Personality prior to disability determines adaptation: Agreeable individuals recover lost life satisfaction faster and more completely. Psychological Science, 22, 1397-1402. https://doi.org/10.1177/0956797611421790 
Running Head: PRE-EVENT PERSONALITY AS PREDICTOR

Boyce, C. J., Wood, A. M., \& Brown, G. D. A. (2010). The dark side of conscientiousness: Conscientious people experience greater drops in life satisfaction following unemployment. Journal of Research in Personality, 44, 535-539. https://doi.org/10.1016/j.jrp.2010.05.001

Boyce, C. J., Wood, A. M., Daly, M., \& Sedikides, C. (2015). Personality change following unemployment. Journal of Applied Psychology, 100, 991-1011. https://doi.org/10.1037/a0038647

Boyce, C. J., Wood, A. M., \& Ferguson, E. (2016a). For better or for worse: The moderating effects of personality on the marriage-life satisfaction link. Personality and Individual Differences, 97, 61-66. https://doi.org/10.1016/j.paid.2016.03.005

Boyce, C. J., Wood, A. M., \& Ferguson, E. (2016b). Individual differences in loss aversion: Conscientiousness predicts how life satisfaction responds to losses versus gains in income. Personality and Social Psychology Bulletin, 42, 471-84.

Boyce, C. J., Wood, A. M., \& Powdthavee, N. (2013). Is personality fixed? Personality changes as much as 'variable' economic factors and more strongly predicts changes to life satisfaction. Social Indicators Research, 111, 287-305. https://doi.org/10.1007/s11205-012-0006-Z

Caliendo, M., Mahlstedt, R., \& Mitnik, O. A. (2014). Unobservable, But Unimportant? The Influence of Personality Traits (and Other Usually Unobserved Variables) for the Evaluation of Labor Market Policies (SSRN Scholarly Paper No. ID 2487797). Rochester, NY: Social Science Research Network. Retrieved from http://papers.ssrn.com/abstract=2487797

Cameron, A. C., \& Miller, D. L. (2015). A practitioner's guide to cluster-robust inference. Journal of Human Resources, 50, 317-372. https://doi.org/10.3368/jhr.50.2.317 
Running Head: PRE-EVENT PERSONALITY AS PREDICTOR

Caspi, A., \& Shiner, R. L. (2007). Personality Development. In Handbook of Child Psychology. John Wiley \& Sons, Inc. Retrieved from http://onlinelibrary.wiley.com/doi/10.1002/9780470147658.chpsy0306/abstract

Costa, P. T., \& McCrae, R. R. (2006). Age changes in personality and their origins: comment on Roberts, Walton, and Viechtbauer (2006). Psychological Bulletin, 132, 26-28. https://doi.org/10.1037/0033-2909.132.1.26

Daly, M., Delaney, L., Egan, M., \& Baumeister, R. F. (2015). Childhood self-control and unemployment throughout the life span: Evidence from two British cohort studies. Psychological Science, 26, 709-723. https://doi.org/10.1177/0956797615569001

Donnellan, M. B., \& Lucas, R. E. (2008). Age differences in the Big Five across the life span: Evidence from two national samples. Psychology and Aging, 23, 558-566. https://doi.org/10.1037/a0012897

Egan, M., Daly, M., Delaney, L., Boyce, C. J., \& Wood, A. M. (in press). Adolescent conscientiousness predicts lower lifetime unemployment. The Journal of Applied Psychology.

Ferguson, E. (2013). Personality is of central concern to understand health: towards a theoretical model for health psychology. Health Psychology Review, 7(Suppl 1), S32S70. https://doi.org/10.1080/17437199.2010.547985

Ferguson, E., \& Lievens, F. (in press). Future directions in personality, occupational and medical selection: Myths, misunderstandings, measurement, and suggestions. Advances in Health Science Education.

Fleeson, W. (2001). Toward a structure- and process-integrated view of personality: Traits as density distributions of states. Journal of Personality and Social Psychology, 80, $1011-1027$. 
Running Head: PRE-EVENT PERSONALITY AS PREDICTOR

Fleeson, W. (2004). Moving personality beyond the person-situation debate: The challenge and the opportunity of within-person variability. Current Directions in Psychological Science, 13, 83-87.

Heckman, J. J., Malofeeva, L., Pinto, R., \& Savelyev, P. A. (2007). The effect of the Perry Preschool Program on the cognitive and noncognitive skills of its participants. University of Chicago, Department of Economics.

Heckman, J. J., Pinto, R., \& Savelyev, P. (2013). Understanding the mechanisms through which an influential early childhood program boosted adult outcomes. The American Economic Review, 103, 2052-2086. https://doi.org/10.1257/aer.103.6.2052

Heineck, G. (2011). Does it pay to be nice? Personality and earnings in the United Kingdom. Industrial \& Labor Relations Review, 64, 1020-1038. https://doi.org/10.1177/001979391106400509

Heineck, G., \& Anger, S. (2010). The returns to cognitive abilities and personality traits in Germany. Labour Economics, 17, 535-546. https://doi.org/10.1016/j.labeco.2009.06.001

Hounkpatin, H. O., Wood, A. M., Boyce, C. J., \& Dunn, G. (2014). An ExistentialHumanistic View of Personality Change: Co-Occurring Changes with Psychological Well-Being in a 10 Year Cohort Study. Social Indicators Research, 121, 455-470. https://doi.org/10.1007/s11205-014-0648-0

Jackson, J. J., Thoemmes, F., Jonkmann, K., Lüdtke, O., \& Trautwein, U. (2012). Military training and personality trait development: does the military make the man, or does the man make the military? Psychological Science, 23, 270-277. https://doi.org/10.1177/0956797611423545

Jokela, M., Hakulinen, C., Singh-Manoux, A., \& Kivimäki, M. (2014). Personality change associated with chronic diseases: pooled analysis of four prospective cohort studies. 
Running Head: PRE-EVENT PERSONALITY AS PREDICTOR

Psychological Medicine, 44, 2629-2640.

https://doi.org/10.1017/S0033291714000257

Kesavayuth, D., Rosenman, R. E., \& Zikos, V. (2015). Personality and health satisfaction. Journal of Behavioral and Experimental Economics, 54, 64-73. https://doi.org/10.1016/j.socec.2014.11.005

Lang, F. R. (2005). Erfassung des kognitiven leistungspotenzials und der 'Big Five' mit computer-assisted-personal-interviewing (CAPI): Zur reliabilität und validität zweier ultrakurzer tests und des BFI-S - Assessment of cognitive capabilities and the Big Five with computer-assisted personal interviewing (CAPI): Reliability and validity]. Berlin: DIW Berlin.

Lang, F. R., John, D., Lüdtke, O., Schupp, J., \& Wagner, G. G. (2011). Short assessment of the Big Five: robust across survey methods except telephone interviewing. Behavior Research Methods, 43, 548-567. https://doi.org/10.3758/s13428-011-0066-z

Lucas, R. E., \& Donnellan, B. M. (2011). Personality development across the life span: Longitudinal analyses with a national sample from Germany. Journal of Personality and Social Psychology, 101, 847-861. https://doi.org/10.1037/a0024298

Lüdtke, O., Roberts, B. W., Trautwein, U., \& Nagy, G. (2011). A random walk down university avenue: life paths, life events, and personality trait change at the transition to university life. Journal of Personality and Social Psychology, 101, 620-637. https://doi.org/10.1037/a0023743

Luhmann, M., Orth, U., Specht, J., Kandler, C., \& Lucas, R. E. (2014). Studying changes in life circumstances and personality: It's about time. European Journal of Personality, $28,256-266$.

McCrae, R. R., Costa, P. T. J., Ostendorf, F., Angleitner, A., \& Avia, M. D. (2000). Nature over nurture: Temperament, personality, and life span development. Journal of Personality and Social Psychology, 78, 173-186. 
Running Head: PRE-EVENT PERSONALITY AS PREDICTOR

Pai, M., \& Carr, D. (2010). Do personality traits moderate the effect of late-life spousal loss on psychological distress? Journal of Health and Social Behavior, 51, 183-199. https://doi.org/10.1177/0022146510368933

Proto, E., \& Rustichini, A. (2015). Life satisfaction, income and personality. Journal of Economic Psychology, 48, 17-32. https://doi.org/10.1016/j.joep.2015.02.001

Rentfrow, P. J., Gosling, S. D., \& Potter, J. (2008). A theory of the emergence, persistence, and expression of geographic variation in psychological characteristics. Perspectives on Psychological Science, 3, 339-369.

Roberts, B. W., Caspi, A., \& Moffitt, T. E. (2003). Work experiences and personality development in young adulthood. Journal of Personality and Social Psychology, 84, 582-593. https://doi.org/10.1037/0022-3514.84.3.582

Roberts, B. W., Walton, K. E., \& Viechtbauer, W. (2006a). Patterns of mean-level change in personality traits across the life course: a meta-analysis of longitudinal studies. Psychological Bulletin, 132, 1-25. https://doi.org/10.1037/0033-2909.132.1.1

Roberts, B. W., Walton, K. E., \& Viechtbauer, W. (2006b). Personality traits change in adulthood: reply to Costa and McCrae (2006). Psychological Bulletin, 132, 29-32. https://doi.org/10.1037/0033-2909.132.1.29

Roberts, B. W., Wood, D., \& Caspi, A. (2008). The development of personality traits in adulthood. In O. P. John, R. W. Robins, \& L. A. Pervin (Eds.), Handbook of personality: Theory and research (3rd ed.) (pp. 375-398). New York, NY, US: Guilford Press.

Rubin, D. B. (2004). Multiple Imputation for Nonresponse in Surveys. John Wiley \& Sons. Rustichini, A., DeYoung, C. G., Anderson, J. C., \& Burks, S. V. (2012). Toward the Integration of Personality Theory and Decision Theory in the Explanation of Economic and Health Behavior (SSRN Scholarly Paper No. ID 2119057). Rochester, 
Running Head: PRE-EVENT PERSONALITY AS PREDICTOR

NY: Social Science Research Network. Retrieved from http://papers.ssrn.com/abstract=2119057

Schafer, J. L., \& Graham, J. W. (2002). Missing data: our view of the state of the art. Psychological Methods, 7, 147.

Soto, C. J., \& Luhmann, M. (2013). Who can buy happiness? Personality traits moderate the effects of stable income differences and income fluctuations on life satisfaction. Social Psychological and Personality Science, 4, 46-53. https://doi.org/10.1177/1948550612444139

Specht, J., Egloff, B., \& Schmukle, S. C. (2011). Stability and change of personality across the life course: the impact of age and major life events on mean-level and rank-order stability of the Big Five. Journal of Personality and Social Psychology, 101, 862-882. https://doi.org/10.1037/a0024950

Specht, J., Egloff, B., \& Schmukle, S. C. (2013). Examining mechanisms of personality maturation: The impact of life satisfaction on the development of the Big Five personality traits. Social Psychological and Personality Science, 4, 181-9.

StataCorp. (2011). Stata Statistical Software: Release 12. College Station, TX: StataCorp LP. Uysal, S. D., \& Pohlmeier, W. (2011). Unemployment duration and personality. Journal of Economic Psychology, 32, 980-992. https://doi.org/10.1016/j.joep.2011.03.008

Wagner, G., Frick, J., \& Schupp, J. (2007). The German Socio-Economic Panel Study (SOEP): Scope, Evolution and Enhancements (SOEPpapers on Multidisciplinary Panel Data Research No. 1). DIW Berlin, The German Socio-Economic Panel (SOEP). Retrieved from http://econpapers.repec.org/paper/diwdiwsop/diw_5fsp1.htm

White, I. R., Royston, P., \& Wood, A. M. (2011). Multiple imputation using chained equations: Issues and guidance for practice. Statistics in Medicine, 30, 377-399. https://doi.org/10.1002/sim.4067 
Running Head: PRE-EVENT PERSONALITY AS PREDICTOR

Wood, A. M., \& Boyce, C. J. (2014). Personality, an overview. In A. C. Michalos (Ed.), Encyclopedia of Quality of Life Research (pp. 4773-4775). Dordrecht, Netherlands: Springer.

Yap, S. C. Y., Anusic, I., \& Lucas, R. E. (2012). Does personality moderate reaction and adaptation to major life events? Evidence from the British Household Panel Survey. Journal of Research in Personality, 46, 477-488. https://doi.org/10.1016/j.jrp.2012.05.005

Zhao, K., Ferguson, E., \& Smillie, L. D. (in press). When fair is not equal: Compassion and politeness predict allocations of wealth under different norms of equity and need. Social Psychological and Personality Science.

\section{Appendix}

In the questionnaire section of the SOEP entitled "What kind of personality do you have?" individuals are asked whether they see themselves as someone who...

1. ...does a thorough job

2. ...is communicative, talkative

3. ...is sometimes somewhat rude to others

4. ...is original, comes up with new ideas

5. ...worries a lot

6. ...has a forgiving nature

7. ...tends to be lazy

8. ...is outgoing, sociable

9. ...values artistic experiences

10. ...gets nervous easily

11. ...does things effectively and efficiently

12. ... is reserved

13. ... is considerate and kind to others 


\section{Running Head: PRE-EVENT PERSONALITY AS PREDICTOR}

14. ...has an active imagination

15. ...is relaxed, handles stress well

Individuals are asked whether the statement applies to them on a 1 to 7 scale, with 1 meaning the statement does not apply to them at all and 7 that it applies perfectly. Questions 3, 6 and 13 relate to the agreeableness scale; 1,7 and 11 relate to the conscientiousness scale; 2,8 and 12 relate to the extraversion scale; 5, 10 and 15 relate to the neuroticism scale; and 4, 9 and 14 relate to the openness-to-experience scale. Scores for each of the traits are obtained by aggregating across each of the three-items by trait after reverse coding questions $3,7,12,15$. 
Table 1: Ordinary Least Squares regressions predicting personality change over 9 years from the occurrence of various socio-economic events using the German Socio-Economic Panel survey 2005-2013
(1)
(2)
(3)
(4)

(5)

Residualized changes in:

Openness Conscientiousness Extraversion Agreeableness Neuroticism

\begin{tabular}{|c|c|c|c|c|c|}
\hline \multicolumn{6}{|l|}{ Occurrence of: } \\
\hline $\begin{array}{l}\text { Unemployment 2005-2013 } \\
N=6,524\end{array}$ & $\begin{array}{l}-0.002 \\
(0.030)\end{array}$ & $\begin{array}{c}-0.086^{* * * *} \\
(0.032)\end{array}$ & $\begin{array}{l}-0.003 \\
(0.030)\end{array}$ & $\begin{array}{l}-0.002 \\
(0.032)\end{array}$ & $\begin{array}{l}0.084 * * * \\
(0.031)\end{array}$ \\
\hline $\begin{array}{l}\text { Retirement 2005-2013 } \\
N=4,001\end{array}$ & $\begin{array}{l}-0.072 * \\
(0.041)\end{array}$ & $\begin{array}{c}-0.140 * * * \\
(0.043)\end{array}$ & $\begin{array}{c}0.005 \\
(0.040)\end{array}$ & $\begin{array}{c}0.011 \\
(0.044)\end{array}$ & $\begin{array}{l}0.074 * \\
(0.042)\end{array}$ \\
\hline $\begin{array}{l}\text { Marriage } 2005-2013 \\
\mathrm{~N}=3,184\end{array}$ & $\begin{array}{l}-0.036 \\
(0.037)\end{array}$ & $\begin{array}{c}0.013 \\
(0.039)\end{array}$ & $\begin{array}{c}0.003 \\
(0.037)\end{array}$ & $\begin{array}{l}-0.022 \\
(0.038)\end{array}$ & $\begin{array}{c}0.052 \\
(0.038)\end{array}$ \\
\hline $\begin{array}{l}\text { Separation } 2005-2013 \\
N=8,653\end{array}$ & $\begin{array}{c}0.051 \\
(0.044)\end{array}$ & $\begin{array}{c}0.096 * * \\
(0.047)\end{array}$ & $\begin{array}{l}0.081 * \\
(0.043)\end{array}$ & $\begin{array}{l}0.131 * * * \\
(0.046)\end{array}$ & $\begin{array}{c}-0.109 * * \\
(0.045)\end{array}$ \\
\hline $\begin{array}{l}\text { Divorce } 2005-2013 \\
N=8,134\end{array}$ & $\begin{array}{l}0.078 * \\
(0.047)\end{array}$ & $\begin{array}{l}0.091 * \\
(0.050)\end{array}$ & $\begin{array}{c}0.093 * * \\
(0.047)\end{array}$ & $\begin{array}{l}0.146 * * * \\
(0.050)\end{array}$ & $\begin{array}{l}-0.039 \\
(0.048)\end{array}$ \\
\hline $\begin{array}{l}\text { Widowhood 2005-2013 } \\
N=8,311\end{array}$ & $\begin{array}{l}-0.005 \\
(0.051)\end{array}$ & $\begin{array}{l}-0.075 \\
(0.054)\end{array}$ & $\begin{array}{c}0.062 \\
(0.050)\end{array}$ & $\begin{array}{c}0.087 \\
(0.054)\end{array}$ & $\begin{array}{c}-0.167 * * * \\
(0.052)\end{array}$ \\
\hline \multicolumn{6}{|c|}{$\begin{array}{l}\text { Table notes: Robust standard errors in parentheses } * * * \mathrm{p}<0.01,{ }^{*} \mathrm{p}<0.05, * \mathrm{p}<0.1 \text {. We carried out a regression for each of } \\
\text { the socio-economic events for all five of FFM personality traits separately. This resulted in } 30 \text { individual regressions } \\
\text { predicting whether individuals experienced the socio-economic circumstance at any point across the nine years. In each } \\
\text { regression individuals who remained in the socio-economic condition under investigation were excluded from the regression. } \\
\text { Each regression includes year and regional dummy variables, sex, age, age }{ }^{2}, a^{3} \text {, education, logarithm of household income } \\
\text { and household size, and disability status at the first time-point as controls. }\end{array}$} \\
\hline
\end{tabular}


Table 2: Bivariate correlations between changes in life satisfaction and personality

\begin{tabular}{llllll}
\hline & $\Delta$ Openness & $\Delta$ Conscientiousness & $\Delta$ Extraversion & $\Delta$ Agreeableness & $\Delta$ Neuroticism \\
$\Delta$ Life Satisfaction & $.06^{* * *}$ & $.10^{* * *}$ & $.11^{* * *}$ & $.07 * *$ & $-.16^{* * *}$ \\
$\Delta$ Openness & - & $.15^{* * *}$ & $.25^{* * *}$ & $.09 * * *$ & $-.04^{* * *}$ \\
$\Delta$ Conscientiousness & - & - & $.16^{* * *}$ & $.26^{* * *}$ & $-.10^{* * *}$ \\
$\Delta$ Extraversion & - & - & - & $-.10^{* * *}$ & $-.12^{* * *}$ \\
$\Delta$ Agreeableness & - & - & - & $-.13 * * *$ \\
$\Delta$ Neuroticism & - & - & - & - & - \\
\hline
\end{tabular}

Table notes: $* * * \mathrm{p}<0.01, * * \mathrm{p}<0.05,{ }^{*} \mathrm{p}<0.1$. 
Table 3: Probit regressions predicting the occurrence of various socio-economic events between 2005 and 2013 with pre- or post-event personality using the German Socio-

Economic Panel survey

\begin{tabular}{|c|c|c|c|c|c|c|c|c|c|c|c|c|}
\hline \multirow[b]{2}{*}{ Dependent variables: } & (1) & (2) & (3) & (4) & (5) & (6) & (7) & (8) & (9) & (10) & $(11)$ & (12) \\
\hline & \multicolumn{2}{|c|}{ Unemployed } & \multicolumn{2}{|c|}{ Retired } & \multicolumn{2}{|c|}{ Married } & \multicolumn{2}{|c|}{ Separated } & \multicolumn{2}{|c|}{ Divorced } & \multicolumn{2}{|c|}{ Widowed } \\
\hline \multicolumn{13}{|l|}{ Independent variables: } \\
\hline \multirow[t]{2}{*}{ Openness at $\mathrm{T} 1$} & $0.038^{*}$ & & 0.044 & & 0.018 & & 0.028 & & 0.040 & & $-0.065 * *$ & \\
\hline & $(0.023)$ & & $(0.031)$ & & $(0.029)$ & & $(0.028)$ & & $(0.030)$ & & $(0.030)$ & \\
\hline \multirow[t]{2}{*}{ Conscientiousness at $\mathrm{T} 1$} & $0.041 *$ & & -0.007 & & 0.002 & & -0.039 & & -0.004 & & 0.014 & \\
\hline & $(0.022)$ & & $(\mathbf{0 . 0 3 3 )}$ & & $(0.027)$ & & $(0.028)$ & & $(0.030)$ & & $(0.034)$ & \\
\hline \multirow[t]{2}{*}{ Extraversion at T1 } & $-0.050 * *$ & & -0.025 & & 0.019 & & 0.036 & & $0.051 *$ & & 0.030 & \\
\hline & $(0.022)$ & & $(0.033)$ & & $(0.028)$ & & $(0.027)$ & & $(0.030)$ & & $(0.033)$ & \\
\hline \multirow[t]{2}{*}{ Agreeableness at T1 } & $-0.052 * *$ & & -0.032 & & -0.006 & & -0.034 & & -0.023 & & -0.031 & \\
\hline & $(\mathbf{0 . 0 2 2})$ & & $(0.031)$ & & $(0.028)$ & & $(\mathbf{0 . 0 2 7})$ & & $(\mathbf{0 . 0 2 9})$ & & $(0.033)$ & \\
\hline \multirow[t]{2}{*}{ Neuroticism at T1 } & $0.065 * * *$ & & 0.017 & & -0.021 & & $0.057 * *$ & & $0.074 * * *$ & & $-0.067 * *$ & \\
\hline & $(0.022)$ & & $(0.031)$ & & $(0.028)$ & & $(0.027)$ & & $(0.029)$ & & $(0.031)$ & \\
\hline \multirow[t]{2}{*}{ Openness at T3 } & & 0.025 & & -0.023 & & -0.010 & & 0.020 & & 0.046 & & -0.043 \\
\hline & & $(0.022)$ & & $(\mathbf{0 . 0 3 2})$ & & $(0.028)$ & & $(0.028)$ & & $(0.031)$ & & $(0.033)$ \\
\hline \multirow[t]{2}{*}{ Conscientiousness at $\mathrm{T} 3$} & & -0.036 & & $-\mathbf{0 . 0 8 8} * * *$ & & 0.016 & & 0.012 & & 0.021 & & $-0.057 *$ \\
\hline & & $(0.022)$ & & $(\mathbf{0 . 0 3 2})$ & & $(0.027)$ & & $(0.027)$ & & $(0.030)$ & & $(0.034)$ \\
\hline \multirow[t]{2}{*}{ Extraversion at T3 } & & -0.021 & & 0.017 & & 0.028 & & 0.032 & & 0.043 & & $0.057^{*}$ \\
\hline & & $(0.022)$ & & $(0.033)$ & & $(0.028)$ & & $(0.028)$ & & $(0.030)$ & & $(0.034)$ \\
\hline \multirow[t]{2}{*}{ Agreeableness at T3 } & & -0.003 & & 0.019 & & -0.016 & & 0.036 & & $0.060 * *$ & & 0.035 \\
\hline & & $(\mathbf{0 . 0 2 2})$ & & $(0.031)$ & & $(0.028)$ & & $(0.027)$ & & $(0.029)$ & & $(0.034)$ \\
\hline \multirow[t]{2}{*}{ Neuroticism at T3 } & & $0.082 * * *$ & & 0.058 & & 0.026 & & -0.011 & & 0.029 & & $-0.114 * * *$ \\
\hline & & $(0.022)$ & & $(0.031)$ & & $(0.027)$ & & $(\mathbf{0 . 0 2 8})$ & & $(0.030)$ & & $(0.033)$ \\
\hline \multirow[t]{2}{*}{ Constant } & $8.352 * * *$ & $8.084 * * *$ & $-48.466 * * *$ & $48.816^{* * *}$ & $-6.994 * * *$ & $-7.007 * * *$ & $-6.428 * * *$ & $-6.291 * * *$ & $-5.217 * * *$ & $-5.190 * * *$ & $-2.455 * *$ & $-2.311 * *$ \\
\hline & $(0.689)$ & $(0.685)$ & $(14.180)$ & $(14.163)$ & $(0.604)$ & $(0.599)$ & $(0.709)$ & $(0.701)$ & $(1.103)$ & (1.107) & $(1.165)$ & (1.117) \\
\hline Observations & 6,524 & 6,524 & 4,001 & 4,001 & 3,184 & 3,184 & 8,653 & 8,653 & 8,134 & 8,134 & 8,311 & 8,311 \\
\hline
\end{tabular}

Table notes: Robust standard errors in parentheses $* * * \mathrm{p}<0.01, * * \mathrm{p}<0.05, * \mathrm{p}<0.1$. Emboldened numbers show that a $\chi 2$ test illustrated significant differences in the

coefficients across models $(p<.05)$. Each regression includes year and regional dummy variables, sex, age, age ${ }^{2}$, age ${ }^{3}$, education, logarithm of household income and household size, and disability status at the first time-point as controls. 
Table 4: Within-person regressions with individual clustering predicting how changes in socio-economic events occurring at $\mathrm{T}$ influenced changes in life satisfaction at $\mathrm{T}$ moderated by pre- or post-event personality using the German Socio-Economic Panel survey from 2005 to 2013

(1) (2)

Dependent variable at T: Life satisfaction

Regression 1: $\quad$ Regression 2:

Independent variables at T:

Unemployed

$-0.301 * * *$

(0.022)

Openness*Unemployed

0.023

$(0.025)$

Conscientiousness*Unemployed

$-0.076 * * *$

$(\mathbf{0 . 0 2 3 )}$

Extraversion*Unemployed

0.026

$(0.023)$

Agreeableness*Unemployed

$-0.010$

(0.023)

0.014

$(0.023)$

Retired

0.035*

(0.020)

Openness*Retired

0.026

$(0.019)$

Conscientiousness*Retired

$-0.023$

$(0.020)$

Extraversion*Retired

Agreeableness*Retired

$-0.032$

$(0.021)$

0.004

$(0.020)$

Neuroticism*Retired

\section{Married}

$-0.006$

$(0.020)$

0.027

$(0.025)$

0.010

$(0.023)$

$-0.022$

(0.022)

$0.053 * *$

$(0.025)$

$-0.061 * *$

(0.026)

0.019

(0.022)

$-0.179 * * *$

(0.046)

$-0.021$

(0.048)

Conscientiousness $*$ Separated

0.029

(0.047)

$-0.031$

$(0.045)$

$-0.079$

(0.056)

0.088**

(0.044)
$-0.303 * * *$

(0.022)

0.016

(0.025)

$-0.056 * *$

(0.023)

0.017

(0.024)

$-0.013$

(0.025)

0.014

(0.023)

0.037*

(0.020)

$-0.005$

(0.021)

$-0.012$

(0.020)

0.033

(0.024)

0.011

(0.020)

$\mathbf{- 0 . 0 4 2} * *$

(0.018)

0.034

(0.024)

$-0.031$

(0.023)

0.007

(0.020)

0.061**

(0.024)

$-0.020$

(0.023)

0.002

(0.025)

$\mathbf{- 0 . 1 5 9 * * *}$

(0.046)

$-0.100 * *$

(0.051)

0.065

(0.048)

$-0.000$

(0.051)

-0.085 *

(0.048)

$-0.045$

(0.044)

(3)

Difference in coefficients - F-statistic 
(1)

(2)

(3)

Dependent variables: Life satisfaction

Regression 1:

Regression 2:

Difference in 2005 Personality (Pre-event) 2013 Personality (Post-event) coefficients - F-statistic

Independent variables:

Divorced

0.076*

$(\mathbf{0 . 0 4 4 )}$

Openness*Divorced

$-0.051$

$(0.045)$

Conscientiousness*Divorced

$-0.068$

$(0.046)$

$-0.026$

(0.045)

$-\mathbf{0 . 0 8 1 *}$

$(\mathbf{0 . 0 4 4 )}$

0.003

$(0.041)$

$-0.099 *$

$(\mathbf{0 . 0 5 7 )}$

0.040

(0.067)

$-0.123 *$

(0.064)

$-0.044$

$(0.066)$

$-0.027$

$(0.057)$

0.048

(0.063)

Neuroticism*Widowed
$0.087 * *$

(0.043)

$-0.115 * *$

(0.046)

0.014

(0.044)

0.038

$(0.045)$

$-0.037$

(0.043)

$-0.099 * *$

(0.041)

$-0.126 * *$

(0.057)

$-0.006$

(0.067)

$-0.072$

(0.061)

0.051

$(0.062)$

0.079

(0.065)

$-0.055$

(0.065)

85,280
0.61

$6.74 * * *$

0.59

0.46

1.56

$2.79 *$

2.58

Observations

85,280

9,574

Number of individuals

9,574

Table notes: Robust standard errors in parentheses $* * * \mathrm{p}<0.01,{ }^{* *} \mathrm{p}<0.05,{ }^{*} \mathrm{p}<0.1$. The exact same data from the same individuals is used across both regressions with the only difference being the time-point in which personality was measured for the personality-event interaction terms. Each regression includes year and regional dummy variables, sex, education, logarithm of household income and household size, and disability status as controls. Since this is a within-person analysis age variables were not included. There was a small amount of missing data. For those that did not report their occupational or marital status we included additional dummies to indicate whether each variable was missing. We dealt with the remaining missing data using multiple imputations. 